\title{
NOTAS SOBRE BURLA Y SACRALIDAD EN EL CONCEPTISMO RELIGIOSO
}

\author{
Armando Pego Puigbó \\ FAcUltat De Filosofia \\ UNIVERSITAT RAMON LLULL
}

1. Algunas delimitaciones históricas y teóricas del conceptismo religioso.

El conceptismo religioso es, al mismo tiempo, un aspecto apasionante y muy árido del conjunto de la poesía aureosecular, a caballo entre la estética manierista y la barroca. Afecta a un conjunto inmenso de composiciones esparcidas por los Cancioneros religiosos de la segunda mitad del siglo XVI y primer cuarto del siglo XVII. La mayoría de ellas carecen de inspiración y resultan casi siempre sumamente repetitivas. En esto no se diferencian mucho de sus precedentes profanos del siglo XV. Ahora bien, si éstos constituyen una fuente de primera mano para trazar el arco inicial de la evolución lírica castellana que culminará en una reinterpretación paradigmática del modelo poético italiano, las antologías religiosas representan la fragmentación escolar, tanto retórica como piadosa, de un magnífico universo literario y espiritual. 
Podría ser útil detenernos, para comenzar, en unas cuestiones terminológicas que, aplicadas a algunos poemas concretos, pueden arrojar alguna luz sobre la necesidad de estudiar, pese a todo, esta clase de poesía si de verdad se quiere profundizar en el desarrollo de la evolución lírica del siglo XVII. De hecho, últimamente retorna el interés por las Rimas sacras de Lope. Sin las composiciones religiosas del último tercio del siglo XVI se pierde parte del horizonte literario que enmarcan - incluso como parodia seria - el experimento lopesco como el más logrado de todos ellos. En este sentido, el conceptismo sacro, que incluye una veta burlesca a contrapié, desempeña un papel no pequeño.

Desde el punto de vista teórico, resulta complicado tratar de analizarlos con la horma de la categoría de la imitación. Si se me permite el anacronismo, casi podría decirse de ellos que reproducen en serie unos modelos que han perdido cualquier "aura" poética. Son unos modelos extremamente fijos que afectan a la composición del texto desde sus niveles macroestructurales hasta decisiones microestilísticas; es decir, suponen la elección de metros, tipos de composiciones y hasta géneros cuya tipificación está plenamente asumida en función de un lenguaje, normalmente coloquial e incluso vulgar, con un carácter completamente tópico.

Si en el Renacimiento, los géneros eran cauces de comunicación poética, ya sea en prosa o en verso, con los que experimentar literaria y vitalmente, la paradójica y creciente obsesión prescriptiva del Manierismo encuentra en la poesía religiosa un fiel y doméstico servidor. El Barroco resuelve estas contradicciones haciéndolos saltar por los aires, arrastrando consigo en fabuloso y cegador apocalipsis crepuscular la estética - y la retóricaclasicistas. Mucho más modestos en sus objetivos, los poemas religiosos reflejaban un agotamiento existencial y creador más profundo de lo que normalmente se cree.

Frente a lo que pudiera parecer, no nos encontramos ante unas poesías que transmiten el ideario contrarreformista, pese a la insistencia, por ejemplo, en el tema de la doctrina eucarística. Más bien, en ellos se destacan los aspectos más superficiales del nuevo paradigma ideológico que vivía la España de Felipe II. No recogen las grandes polémicas en torno a la cuestión De auxiliis que enfrentó durísimamente a dominicos y jesuitas españoles al comienzo del siglo XVII; ni siquiera se hacen eco de las polémicas espirituales de la época, como, por ejemplo, la que tiene como protagonista la reforma 
carmelitana emprendida - también en el terreno de la poesía - por Juan de la Cruz y Teresa de Ávila. Prefieren repetir una y otra vez los motivos más "espectaculares" de la liturgia y el culto católicos: los principales ciclos del año (Navidad, Pasión, Pascua) y la devoción a la Virgen, a los santos y a la Eucaristía.

Su reflexión poética no es tampoco la de Sánchez de las Brozas ni la de Fernando de Herrera, ni muchísimo menos. Donde se mueven cómodamente estos poetas es entre manuales escolares, como el de Miguel Sánchez Lima (El arte poético en romance castellano, 1580) y, sobre todo el de Juan Díaz Rengifo (Arte poética española, 1592). Por ejemplo, en su Cancionero religioso de juventud Francisco de Medrano emplea en varias ocasiones como modelo a fray Luis de León, normalmente en composiciones cuya atribución actualmente es dudosa. ${ }^{1}$ Sobresale por su extensión una serie larguísima de tercetos en la extensa e incompleta composición titulada Estímulo de amor divino, homónima de la que apareció en el Arte poética española de Juan Díaz de Rengifo como Estímulo del divino amor, atribuida por fray Bautista de Lisaca en el siglo XVII a fray Luis de León. ${ }^{2}$

Este ejemplo podría multiplicarse comparando composiciones de poetas desde Damián Vegas hasta José de Valdivielso. Se recoge un misma estrofa, unos mismos motivos y unos mismos estilemas y se estiran al máximo, hasta que se logra que quede claro que han dado de sí. Parece, pues, un tipo de poesía que podría hacer las delicias de clasificaciones ortodoxamente estructuralistas, cuyo interés, más allá de este ámbito, podría atañer, en todo caso, a un mejor conocimiento de la estructura y la variedad de los certámenes poéticos habituales en la época.

En primer lugar, es conveniente evitar la tendencia a extrapolar al género de la poesía religiosa uno de sus dispositivos temático y estructural básico, por más relevante y definitorio que sea en nuestra percepción actual. Me refiero, claro está, a los contrafacta o vueltas a lo divino de composiciones profanas. Es evidente que desde Sebastián de Córdoba, que volvió a lo divino la poesía de Garcilaso, ésta es una de las líneas fundamentales de la lírica

\footnotetext{
${ }^{1}$ Este Cancionero acaba de ser editado por Jesús Ponce, con una introducción que enmarca su lugar en la poesía religiosa de la época (Francisco de Medrano, Diversas rimas, edición de Jesús Ponce Cárdenas, Sevilla, Fundación José Manuel Lara, 2005, pp. 213-465).

${ }^{2}$ Romancero y Cancionero sagrados, BAE 35, p. 364. De igual título existía una obra atribuida a San Buenaventura.
} 
culta religiosa. ${ }^{3}$ Una lírica que vuelve los ojos, de manera seria, a la tradición poética petrarquista, sumándose así a la línea hegemónica, de alta cultura, de la poesía de su época. Pero este tipo de poesía religiosa no sólo es que no constituya el único camino o incluso la fórmula dominante sino que en sí mismo se desvía $-\mathrm{y}$ he ahí su originalidad y su mérito, pero también sus límites - del substrato de los cancioneros religiosos quinientistas desde fray Ambrosio de Montesinos.

Más que a Córdoba, imbuido de una aplicación contrarreformista de la imitatio, se debieron primero a Juan del Enzina a fines del siglo XV y después, y sobre todo, al Segundo Cancionero Espiritual de Jorge de Montemayor (1558) los intentos de una profunda renovación métrica, estilística y hasta temática de la poesía religiosa. Aunque sea ésta la línea más interesante, sin embargo no es la queatraviesa predominantemente los cancioneros religiosos de la segunda mitad del siglo XVI, más interesados en repetir alabanzas al Santísimo Sacramento, a la Inmaculada Concepción de María o en exaltar las virtudes de algunos santos, de acuerdo con unos recursos poéticos aplicados mecánicamente.

Al hablar de conceptismo religioso conviene vigilar, por tanto, el uso excesivo de la categoría literaria implicada en él. Uso del ingenio y de la imitación, sí; en algunos casos, incluso, con un alto grado de recreación literaria, que incluye la técnica de los contrafacta. Pero un ingenio y una imitación que no son dotadas de una organicidad compositiva sino que se utilizan como medios de amplificación. Así, las posibilidades burlescas son, normalmente, producto de dilogías chocarreras exprimidas al máximo. No resulta siempre fácil discernir en ellas una intención irreverente, implícita a menudo en las posibilidades perlocutivas del juego verbal. Aun así no se puede afirmar sin ambages que estos juegos conceptuales tengan una base $o$ una finalidad buscadamente burlesca; entre otras cosas, como es lógico, por los riesgos que se corrían en tiempos tan inciertos.

\footnotetext{
${ }^{3}$ Sebastián de Córdoba, Las obras de Boscán y Garcilasso trasladadas en materias Christianas y religiosas, Granada, René Rabut, 1575. Puede verse un extenso capítulo dedicado a un gran número de estas versiones "a lo divino" de Garcilaso desde el último tercio del siglo XVI al primero del siglo XVII en el tomo III de la Historia y Crítica de la poesía lírica culta "a lo divino" en la España del Siglo de Oro (Francisco Javier Sánchez Martínez, "Garcilaso «a lo divino»", De los orígenes a la divinización de la lírica de Garcilaso, Alicante, F. J. Sánchez Martínez, 1996, pp. 59-289).
} 


\section{Subversión burlesca en las Flores de Poetas Ilustres (1605).}

Me detendré primero en dos composiciones de la Segunda Parte de las Flores de poetas ilustres de Pedro de Espinosa (1605) en que este "agnosticismo" literario de los temas religiosos es más llamativo por la soltura casi desvergonzada de su tratamiento. Después, insistiré en el empleo de algunos procedimientos que hacen muy difícil determinar claves burlescas de lectura que, sin embargo, parecen operar subterráneamente. Para esto último, tomaré algunos ejemplos del Cancionero religioso de Francisco de Medrano.

El primer poema está dedicado a san Juan Evangelista y es obra de Pedro Espinosa, cuyas composiciones en las Flores de poetas ilustres - dice Belén Molina - "declaran abiertamente una naturaleza poco espiritual". Escrito en quintillas, Espinosa apostrofra al discípulo amado, reconstruyendo su amistad con Cristo mediante el campo semántico eucarístico que, a lo largo del poema, cobra diversos significados, algunos muy dudosos desde un punto de vista sexual. La imagen nuclear del poema es la intimidad de Juan con Cristo durante la cena pascual. Comienza así la imprecación:

\section{Iuan, aunque soys tan querido, \\ No trateys de regalaros, \\ Estando Christo afligido, \\ Que es mucho regalo, echaros \\ Sobre lo que aveys comido. ${ }^{5}$}

Resulta evidente a lo largo de las estrofas que el poeta no siente simpatía por el autor del cuarto evangelio, que, satisfecho de querer tratar el origen de quien es el Logos eterno, "despues nos hazeys creer / en los sueños que soñays". Diríase que Espinosa siente una extraña mezcla de animadversión y envidia de escritor, que busca en las dilógicas alusiones una compensación sublimada: "O quan alto aquí subís! / Quanto essa pluma os remonta? / Pues si de Christo decís, / Lo infinito que Dios monta / En una plana escrivís". La encomienda de Cristo en la Cruz a Juan para que cuide de su Madre, da pie una vez más para que el poeta andaluz arremeta en tres quintillas contra la

\footnotetext{
${ }^{4}$ Belén Molina Huete, La trama del ramillete. Construcción y sentido de las Flores de poetas ilustres de Pedro Espinosa, Sevilla, Fundación José Manuel Lara, 2003, p. 144.

${ }^{5}$ Pedro Espinosa, Primera parte de la Flores de poetas ilustres, edición facsímil, Madrid, RAE, 1991, f. $195 \mathrm{r}-196 \mathrm{v}$
} 
simonía eclesiástica, pues la Virgen lo nombra capellán por ser su nuevo hijo, así como de nuevo contra su amistad: "Y vuestras manos le dan / La carne a su misma carne, / Como digno capellán, / Aunque ella nos la dio en carne, / $\mathrm{Y}$ vos se la days en pan".

Todas estas connotaciones burlescas que, al mismo tiempo, reflejan alusiones metaliterarias (desde los Evangelios a las leyendas hagiográficas sobre la vida de san Juan), culminan en la quintilla que cierra el poema. En los dos primeros versos es posible descubrir una burla paródica de la mística sanjuanista ("Levantays a Dios el buelo, / sin ser de ninguno visto"). En los tres últimos no habría que descartar que existiese una alusión mitológica condensando el ataque de todo el poema. Se produciría por contaminación e interferencia de elementos culturales que reforzarían tanto la cohesión intratextual como la coherencia extratextual: "Y despidiéndoos del suelo, / Qual gentilhombre de Cristo / En cuerpo entrays en el cielo". El último verso aplica a san Juan la creencia católica de la Asunción. No obstante, desde la descripción de san Pablo de su visión mística (2 Cor.12, 2-4), nada impide un rapto corporal al cielo. En el texto de Espinosa se refuerza esta posibilidad por el uso del presente.

También sorprende el último poema de la antología de Espinosa, precisamente por su posición final. Fue escrito por Salas Barbadillo y está dedicado a san Juan Bautista. Es un soneto en apariencia tópico, que presenta al Bautista como la aurora que anuncia el Sol que es Cristo. Se lisonjea al protagonista en un par de versos del segundo cuarteto: “Y al despertar su luz tan bien cantaste, / Que tu voz le suspende y le enamora" . ${ }^{6}$ En cambio, los dos últimos tercetos presentan un vivísimo contraste anticlimático que coincide con un desplazamiento de perspectiva desde el espacio bucólico al heroico.

El Bautista, que es la "sagrada espada" con que Cristo hace huir a Lucifer, muestra entre aclamaciones "esfuerzo y valentía" para acabar siendo descrito como "espía degollado". La alusión desmitificadora a la trágica muerte de Juan resulta irónica. Sin duda, contiene un eco del Ecce Agnus Dei, pues, siendo el precursor, Juan anticipa escondidamente, con sigilo, la muerte del Cordero de Dios. Así, podría justificarse un tanto forzadamente el uso de la palabra "espía" en su acepción corriente. Es obvio además que se trata de

\footnotetext{
${ }^{6}$ Ibidem, f. 204r-v.
} 
una sustitución eufemística para evitar la fácil imagen de "cordero degollado" que rompe el ritmo.

Pero el sentido evidente del terceto ("Pues mostrando tu esfuerzo y valentía, / siendo reconocido de la tierra, / quedaste como espía degollado") sólo aparece teniendo en cuenta el uso de "espía" como voz de germanía. La edición de 1732 del Diccionario de la Real Academia Española incluía la acepción "en la Germanía significa el que acecha o atalaya". ${ }^{7}$ Remitía sin más especificación al Vocabulario de Juan Hidalgo, que en realidad era una antología de romances de germanía del siglo XVII anotada léxicamente. ${ }^{8}$

Ahora interesa retener, sin embargo, el sustantivo "atalaya", del que deriva el verbo "atalayar", uno de cuyos significados está recogido desde 1726 por la Real Academia y que pervive hasta la última edición de su Diccionario en 2001. En el siglo XVIII se señalaba que era "voz antigua, que significaba el hombre que habita en la torre para registrar la tierra y el mar, y avisar con ahumadas o fuego las novedades que ve. Oy decimos Centinela". Y remachaba "Lo que agora llamamos Centinela, amigos de vocablos extrangeros, llamaban nuestros Españoles en la noche escucha, en el día atalaya; nombre más propio para su oficio". ${ }^{9}$

Por tanto, el terceto en cuestión de Salas Barbadillo se apoya en la palabra "espía" con esta acepción para mantener la sorprendente coherencia semántica de todo el soneto. El Bautista, con su testimonio diurno, avista al Cordero de Dios y lo anuncia a los de su tierra. Por su profesión misma de "atalaya" es asesinado. Quizás sería excesivo atribuirle también un siniestro sarcasmo implícito semánticamente y derivado léxicamente, pues, si hacemos caso de nuevo a Hidalgo, "atalaya" es sinónimo también de "ladrón" en la jerga de germanía. Es muy difícil justificar esta acepción, sin exceder el marco isotópico del poema. Sería, a lo sumo, una alusión a las razones políticas de la muerte del Bautista por haber denunciado el concubinato de Herodes con su cuñada. Aun así, el significado más probable sería el más corriente de "espía". En cualquier caso, parece verosímil inclinarse por la opción de que el Bautista acaba como un "espía degollado" por haber anunciado la luz del mundo a sus compatriotas.

\footnotetext{
${ }^{7}$ Véase la base de datos Nuevo Tesoro Lexicográfico de la Lengua Española incluida en el portal de la Real Academia Española (www.rae.es).

${ }^{8}$ Juan Hidalgo, Romances de germanía de varios autores: con el vocabulario por la oren del a.b.c. para declaración de sus términos y lengua..., Zaragoza, Juan Larumbe, 1644.

${ }^{9}$ Ibidem.
} 


\section{La ambigüedad burlesca del concepto sacro: Francisco de Medrano.}

Por lo que respecta a Francisco de Medrano, es fácil advertir en muchas de sus composiciones, como en la de tantos autores religiosos, los recursos estilísticos que Dámaso Alonso describió a propósito de los romances a San Francisco "Un bulto casi sin bulto" y a la muerte "Al son cuerdo de las cuerdas": derivación, vinculada a la homofonía o cuasi-homofonía; arabescos etimológicos, etc. ${ }^{10}$ Para Alonso, todos estos procedimientos permiten ver a Medrano "ligado a una tradición de artificios de chiste verbal que aparecen una y otra vez en la Edad Media y el Renacimiento temprano y llegan a la segunda mitad del siglo XVI" ${ }^{11}$

Me gustaría señalar, con todo, una extraña composición en que todos estos recursos se combinan con una estrofa heroica (la octava real). Me refiero al poema $A$ San Laurencio mártir. En las dos primeras estrofas se plantea el motivo más conocido del martirio del santo español: colocado en una parrilla con brasas encendidas, Lorenzo pide al emperador Decio que le den la vuelta para estar en su punto. Como puede observarse, la mezcla de lo heroico y lo chusco está permitido por el mismo tema, que, sin embargo, en principio Medrano quiere atemperar:

Espanto ponga verle que convide

a Decio con el lado retostado y dé a garganta ya tan estragada carne con amoroso fuego asada ${ }^{12}$

Ahora bien, a partir de la tercera estrofa la voz del poeta se dirige directamente al santo ("Mirad, levita santo, el alegría”). Según la clasificación de las figuras del receptor lírico realizada por Ángel Luis Luján, Lorenzo formaría parte de aquellos interlocutores especiales "que están a medio camino entre la capacidad y la incapacidad de comunicarse: son muertos, divinidades, personas imaginarias" ${ }^{13}$ El caso típico de esta clase de apóstrofe sería la elegía,

\footnotetext{
${ }^{10}$ A partir de este momento, reaprovecho parte del material incluido en mi artículo inédito "La poesía religiosa de juventud de Francisco de Medrano", el cual aparecerá próximamente en un número monográfico de la revista Canente.

${ }^{11}$ D. Alonso, Vida y obra de Medrano II, Madrid, CSIC, 1948, p. 357.

${ }^{12}$ F. de Medrano, Diversas Rimas, op. cit, p. 244.

${ }^{13}$ Ángel L. Luján, Pragmática del discurso lírico, Madrid, Arco-Libros, 2004, p. 252.
} 
en la cual la voz poética se dirige a un muerto. En el caso presente, sin embargo, Lorenzo, cuya historia se conoce, es interpelado mientras aún vive. Por tanto, la simultaneidad de la voz poética con el interlocutor sólo puede proceder de una dislocación temporal. Dislocación verosímil sólo en el ámbito de la «meditación», concretamente en su aplicación ignaciana, que se basa no sólo en la "composición de lugar" sino en "traer a la memoria" y "hacerse presente" a la historia. Por ello, es posible compaginar el sentido alegórico del relato con la participación de los acontecimientos que incluyen una respuesta del propio Lorenzo:

En medio, pues, del fuego que sufristes, sal de la tierra, mártir, os mostrastes y como tal con fuerza resurgistes y del fuego prestísimo saltastes, a los más altos cielos subistes de donde nunca más acá tornastes porque Dios en la mesa generosa os tiene como sal blanca y sabrosa $[\ldots]$ «Por mostrarles el lado requemado, les ruego y les suplico que me vuelvan, que vuelto lo que sufro mostraré y a Dios a quien me vuelve, volveré» ${ }^{14}$

La alusión evangélica al cristiano como "sal" de la tierra (Mt. 5, 13) (que incluye también la posibilidad homofónica con el verbo "salir", presente en el sintagma de la vocación de Abraham en Gen 12,1) alude en todo caso a una posibilidad isotópica que recorre el poema: el cuerpo de Lorenzo como manjar y, enconsecuencia, connotadoeucarísticamente.Esta posibilidad, paradójicamente, actualiza la dimensión al mismo tiempo seria y humorística que está presente en su fuente: la Legenda aurea (1264) de Jacobo de la Vorágine. ${ }^{15}$

Para Dámaso Alonso "tras las bromas macabras de Medrano, sus ojos de jesuita nos avizoran, angustiados". ${ }^{16}$ Sin descartar esta interpretación

\footnotetext{
${ }^{14}$ F. de Medrano, op. cit., pp. 245-246.

${ }^{15}$ «Luego, volviendo la cabeza hacia donde estaba el emperador, díjole en tono festivo: -Oye, pobre hombre: de este lado ya estoy asado, di a tus esbirros que me den la vuelta; acércate a mí, corta un trozo de mi carne y cómelo, que ya está a punto para ello" (Santiago de la Vorágine, La leyenda dorada, vol. 1, Madrid, Alianza Editorial, 1982, p. 465).

${ }^{16}$ D. Alonso, op. cit., p. 356.
} 
psicológica, conviene reparar que el propio Medrano recupera también el violento choque entre "rigor conceptual de lo divino y chocarrera atracción del mundo de la cocina" que el maestro filológico advertía en unos versos del poeta Miguel Cid, incluido en el manuscrito de justas sevillanas donde Dámaso había descubierto los dos romances de Medrano. Compárese la lira de Cid que citaba en su trabajo sobre Medrano y la siguiente octava del poema a san Lorenzo:

\section{Medrano}

"Es en este banquete convidado Dios, a cuyo sabor vos os guisastes, habiéndoos con el fuego sazonado, donde vuestro saber todo empleastes, porque queriendo dar otro guisado del que dio de sí Dios y vos probastes, daros en carne asada habéis querido, habiéndose dado en pan cocido"17

\author{
Miguel Cid \\ "Habéisos diferenciado \\ de Dios, pues habéis querido \\ dar diferente el guisado, \\ que él dióseos en pan cocido \\ y vos a él en carne asado". ${ }^{18}$
}

Sin duda, esa combinación de un estilo presuntamente elevado con uno bajo para un tema simultáneamente heroico y cómico, a medio camino entre lo eucarístico y lo carnavalescamente gastronómico, sin ser paródico, refleja una época de experimentación que distorsiona el decoro correspondiente a temas y patrones estróficos. Esta tarea, llevada a cabo con excelsa calidad por el trayecto poético de Góngora, también podía recordar la contaminación genérica y temática renacentista entre lo heroico narrativo, lo elegíaco y lo satírico, aunque en un nivel pedestre, conceptual y lingüísticamente deudor de la tradición cancioneril del siglo XV, que había logrado pervivir en el primer Renacimiento como señalara Dámaso Alonso. Con las enormes distancias que lo separan del soberbio romance de Píramo y Tisbe del cordobés, en las octavas de Medrano puede advertirse de modo muy embrionario y sin apenas levantar vuelo lírico el malestar ante una situación poética que no puede ser

\footnotetext{
${ }^{17}$ F. de Medrano, op. cit., pp. 244-245.

${ }^{18} \mathrm{Ibidem}$, p. 355. Miguel D'Ors recoge un romance de Alonso de Ledesma titulado A todos los santos, de temática alimentaria, que incluye una cuarteta dedicada a san Lorenzo, aunque aquí se limita a resaltar la anécdota nuclear del martirio: "Laurencio es el pavo asado, / y anduvo tan diligente / que porque no fuese crudo / dio prisa que le volviesen" (Vida y poesía de Alonso de Ledesma. Contribución al estudio del conceptismo español, Pamplona, Ediciones Universidad de Navarra, 1974, p. 183).
} 
tenida por burlesca sin poder por ello tomarla como completamente seria. La solución final del poema resulta bastante escéptica al respecto, pues el poeta se atreve a considerar que la heroicidad del santo se debiera quizás a falta de resignación cristiana:

$$
\begin{aligned}
& \text { Es porque con mayor tormenta vía } \\
& \text { que la llama por poco se muriera } \\
& \text { y su lado quedara sano y crudo } \\
& \text { y en caso tal estar no quiso mudo } \\
& \text { y un grave dolor sufrir no pudo. }{ }^{19}
\end{aligned}
$$

\section{UnA CODA CRÍtICA.}

Al comenzar comentaba que el tema de la poesía religiosa era, simultáneamente apasionante y muy árido. En un artículo clásico Bruce Wardropper ya alertó de la importancia de la llamada poesía religiosa y quiso destacar su influencia sobre la poesía profana del siglo XVI, frente a la tendencia habitual a resaltar el camino crítico opuesto. ${ }^{20}$ No obstante, la clasificación que ofrecía el crítico norteamericano dejaba de lado aquellas composiciones que, como las que hemos analizado, resultan difíciles de integrar en un esquema apriorísticamente religioso. No creo, con todo, que su estudio, como un afluente del conceptismo religioso, aporte grandes novedades al conocimiento de la gran poesía burlesca barroca.

Sin embargo, es posible que una revisión más profunda de la que he podido esbozar aquí ofrezca datos interesantes tanto desde una perspectiva estrictamente filológica, histórico-crítica, como desde una teórica. La división métrico-genérica, la adscripción temática, la organización macroestructural de los Cancioneros - colectivos o individuales -, así como los elementos estilísticos de disidencia y subversión carnavalesca, habitualmente asociados al ámbito gastronómico y escatológico, pueden ofrecer ángulos nuevos de la transformación social, política y religiosa de la España seiscentista.

\footnotetext{
${ }^{19}$ F. de Medrano, op. cit., p. 246.

${ }^{20}$ Bruce W. Wardropper, «La poesía religiosa del Siglo de Oro", Edad de Oro IV (1985): 195-210.
} 
